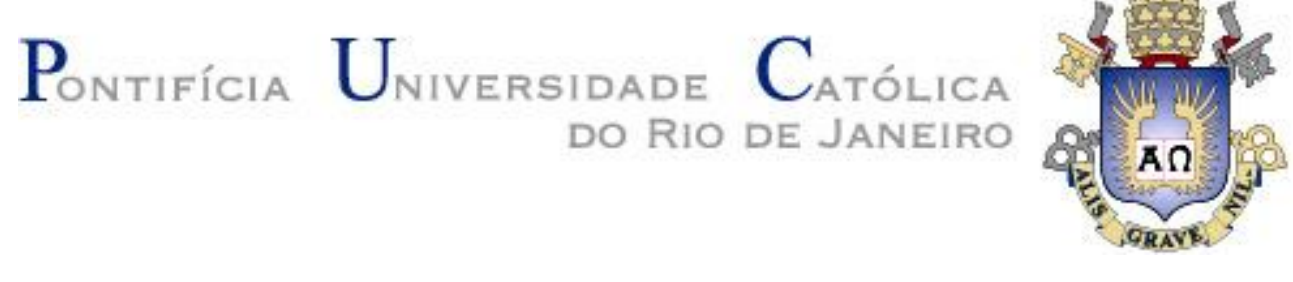

Flavia Cristina S da C Miragaya

\title{
O Efeito dos Retornos Anormais nas Buscas por Informação dos Investidores
}

\section{Dissertação de Mestrado}

\begin{abstract}
Dissertação apresentada como requisito parcial para obtenção de grau de Mestre pelo Programa de PósGraduação em Macroeconomia e Finanças do Departamento de Economia do Centro de Ciências Sociais da PUC-Rio.
\end{abstract}

Orientador: Prof. Pablo Hector Seuanez Salgado Co-Orientador: Prof. Arthur Amorim Bragança 
Flavia Cristina S da C Miragaya

\section{O Efeito dos Retornos Anormais nas Buscas por Informação dos Investidores}

Dissertação apresentada como requisito parcial para obtenção de grau de Mestre pelo Programa de PósGraduação em Macroeconomia e Finanças do Departamento de Economia do Centro de Ciências Sociais da PUC-Rio. Aprovado pela Comissão Examinadora abaixo assinada.

Prof. Pablo Hector Seuanez Salgado Orientador

Departamento de Economia - PUC-Rio

Prof. Arthur Amorim Bragança

Co-Orientador

Departamento de Economia - PUC-Rio

Prof. Marcelo Cunha Medeiros

Departamento de Economia - PUC-Rio

Prof. Ruy Monteiro Ribeiro

Departamento de Economia - PUC-Rio

Prof. Augusto Cesar Pinheiro da Silva Vice-Decano Setorial de Pós-Graduação do

Centro de Ciências Sociais - PUC-Rio

Rio de Janeiro, 31 de julho de 2017 
Todos os direitos reservados. É proibida a reprodução total ou parcial do trabalho sem autorização da universidade, da autora e do orientador.

Flavia Cristina S da C Miragaya

Graduou-se em Economia pela Universidade Federal do Rio de Janeiro (UFRJ) em 2011.

Ficha Catalográfica

Miragaya; Flavia Cristina S da C

O efeito dos retornos anormais nas buscas por informação dos investidores / Flavia Cristina $\mathrm{S}$ da C Miragaya ; orientador: Pablo Hector Seuanez Salgado ; co-orientador: Arthur Amorim Bragança. - 2017.

46 f. : il. color. ; $30 \mathrm{~cm}$

Dissertação (mestrado)-Pontifícia Universidade Católica do Rio de Janeiro, Departamento de Economia, 2017.

Inclui bibliografia

1. Economia - Teses. 2. Hipótese dos mercados eficientes. 3. Arbitragem. 4. Limitações à arbitragem. 5. Google trends. I. Seuanez Salgado, Pablo Hector. II. Bragança, Arthur Amorim. III. Pontifícia Universidade Católica do Rio de Janeiro. Departamento de Economia. IV. Título.

CDD: 330 


\section{Agradecimentos}

Agradeço aos professores Pablo Salgado e Arthur Bragança pela orientação, dedicação e aprendizado durante a elaboração deste trabalho.

À minha mãe Cristina, meu irmão Antonio e ao Marcos por todo apoio, incentivo e paciência.

Aos meus colegas de mestrado, pelo convívio e amizade, especialmente à Mariana Ennes, Ana Luiza Cyrino e Marcus Melo.

Aos professores e funcionários da PUC por participarem da minha formação. À minha família e amigos, pela compreensão e apoio.

Aos membros da banca Marcelo Cunha Medeiros e Ruy Ribeiro pelos comentários construtivos e pela participação. 


\section{Resumo}

Miragaya, Flavia Cristina S da C; Salgado, Pablo Hector Seuanez; Bragança, Arthur Amorim. O efeito dos retornos anormais nas buscas por informação dos investidores. Rio de Janeiro, 2017. 46p. Dissertação de Mestrado - Departamento de Economia, Pontifícia Universidade Católica do Rio de Janeiro.

Neste trabalho, estudo o comportamento dos arbitradores ao se depararem com variações nos níveis de preços das ações, mais especificamente, analisando a forma como eles buscam informações sobre esses ativos. Para isso, testo e confirmo a hipótese de que os retornos anormais das ações levam os investidores a buscarem ativamente mais informações sobre essas empresas, usando dados de volume de buscas no Google. Adicionalmente, analiso de forma separada o impacto de retornos anormais negativos e de retornos anormais positivos sobre o volume de buscas do Google, chegando à conclusão de que os retornos negativos têm um efeito maior sobre o volume de buscas que os efeitos positivos.

\section{Palavras-chave}

Hipótese dos Mercados Eficientes; Arbitragem; Limitações à Arbitragem; Google Trends. 


\section{Abstract}

Miragaya, Flavia Cristina S da C; Salgado, Pablo Hector Seuanez (Advisor). Bragança, Arthur Amorim. (Co-Advisor). The Effect of Abnormal Returns on Investors' Search for Information. Rio de Janeiro, 2017. 46p. Dissertação de Mestrado - Departamento de Economia, Pontifícia Universidade Católica do Rio de Janeiro.

I study the behavior of arbitrageurs when they are faced with changes in stock price levels, more specifically analyzing the way they seek information about these assets. I test and confirm the hypothesis that abnormal stock returns prompt investors to seek actively information about these companies by using Google search volume data. Furthermore, I study the separate effects of negative abnormal returns and positive abnormal returns on Google search volumes, and conclude that negative returns cause a greater impact on the search volumes than positive returns.

\section{Keywords}

Efficient Markets Hypothesis; Arbitrage; Limits to Arbitrage; Google Trends. 


\section{Sumário}

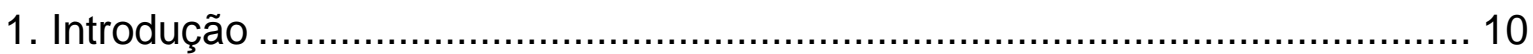

2. Revisão Bibliográfica ........................................................................... 14

2.1. Revisão Teórica ....................................................................... 14

2.2. Literatura Google Trends ............................................................... 19

3. Análise de Dados e Metodologia Empírica.................................................... 22

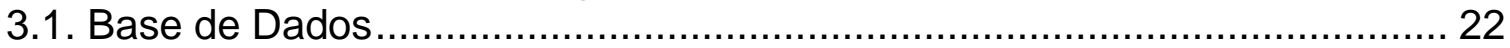

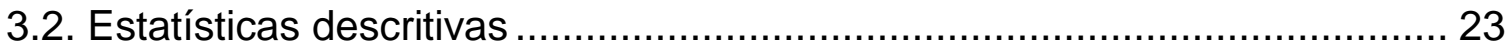

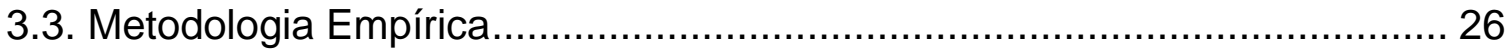

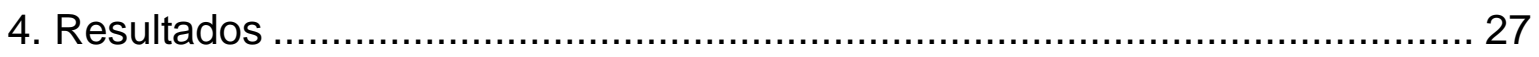

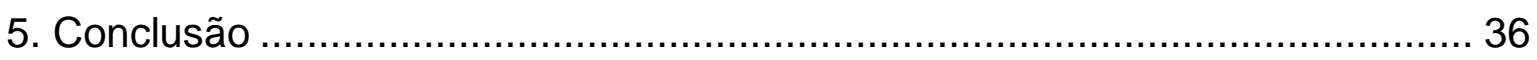

6. Referências Bibliográficas ...................................................................... 38

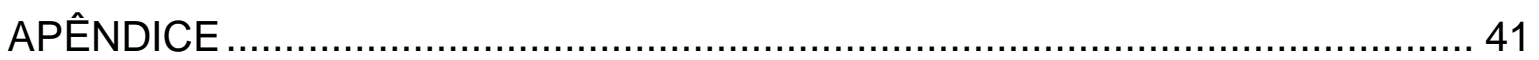

A. Google Trends - A Ferramenta ............................................................... 41

B. Google Trends - Obtenção e Tratamento dos Dados ................................. 42

C. Resultados das Regressões com Variáveis do Google em Nível ..................... 43 


\section{Lista de figuras}

Figura 1: Função Utilidade da Teoria do Prospecto ......................................... 19

Figura 2: Média dos dados de volume de buscas no Google ao longo do período estudado de janeiro de 2007 a dezembro de 2016

Figura 3: Número de dispositivos móveis wireless conectáveis à Internet em uso no Brasil.

Figura 4: Persistência dos efeitos dos retornos anormais no volume de buscas no Google. 32

Figura 5: Resultados da pesquisa pelo termo "IBOV" 42 


\section{Lista de tabelas}

Tabela I: Estatísticas Descritivas de Frequência de Buscas no Google................ 24

Tabela II: Número de Empresas por Setor .................................................... 26

Tabela III: Impacto dos Retornos Anormais no Volume de Buscas no Google .... 30

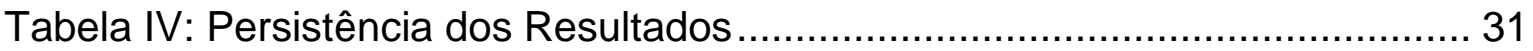

Tabela V: Impacto dos Retornos Anormais no Volume de Buscas no Google:

Decompondo Retornos em Positivos e Negativos ............................. 34

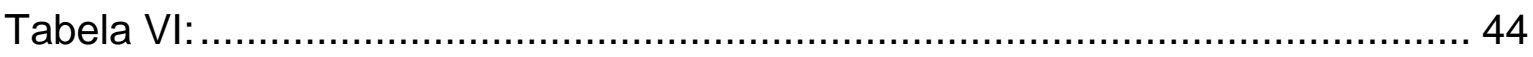

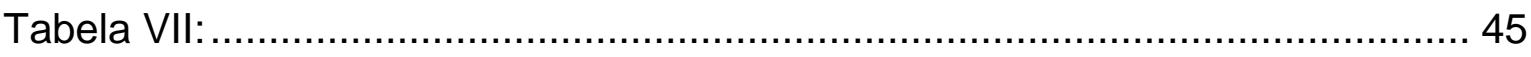

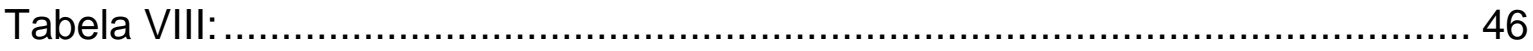




\section{1.}

\section{Introdução}

Em modelos teóricos de apreçamento de ativos, os arbitradores desempenham um papel fundamental no equilíbrio do mercado financeiro. Nos modelos racionais, quando o preço de um ativo se afasta do seu valor fundamental, os arbitradores agem rapidamente comprando ou vendendo o ativo em questão, trazendo o seu valor de volta para os patamares de preço corretos. Neste trabalho, estudo como o arbitrador realiza esforços para obter informações sobre os ativos que são negociados no mercado em que ele atua, que é um prérequisito para realizar seu papel.

Segundo a Hipótese dos Mercados Eficientes, os preços de ativos refletem toda informação disponível no mercado. Flutuações infundamentadas no mercado são rapidamente eliminadas por arbitradores que, ao perceberem as oportunidades de arbitragem, levam o valor do ativo de volta para o seu valor real. Quando uma nova informação surge, a notícia se espalha pelo mercado e é quase imediatamente incorporada aos preços dos ativos (Shleifer (2000)). Assim, quando o arbitrador observa um retorno anormal, ele percebe duas possíveis causas: ou novas informações surgiram no mercado, alterando a percepção dos fundamentos da empresa, ou há uma possibilidade de arbitragem. Para discernir entre as duas alternativas, o arbitrador precisa se informar para compreender o que está ocasionando as variações nos preços dos ativos de interesse dele.

No modelo de Grossman e Stiglitz (1980), os retornos de investidores informados obtêm retornos maiores do que aqueles que não buscam informações. Há evidências empíricas que corroboram essa premissa. Larcker e Lys (1987) e Mitchell e Pulvino (2001) encontram que arbitradores que adquirem informações superiores sobre reorganizações societárias de empresas obtêm retornos substancialmente maiores. Os trabalhos de Seyhun (1986) e Jeng et al (2003) indicam que investidores com informações privilegiadas obtêm retornos anormais mesmo ao realizar transações de forma legal. Seyhun (1986) encontra evidências de que transações feitas por investidores com informações privilegiadas (executivos de empresas) preveem os movimentos do mercado. 
Embora seja amplamente aceito que o arbitrador realiza esforços para adquirir informação, há poucos estudos que documentam os mecanismos usados para a obtenção de informação. Com esse objetivo, realizo um estudo usando dados do Google Trends e dados de retornos das empresas componentes do Índice Ibovespa. Os dados de volume de buscas no Google foram coletados manualmente no site do Google Trends (https://trends.google.com.br/) com intuito de construir uma base de dados com a frequência de buscas de todas as empresas estudadas. Essa frequência de buscas é utilizada como uma proxy pela busca de informações sobre ações realizadas por investidores. Já os dados de retornos das empresas do Índice Ibovespa foram utilizados para construir medidas de retornos anormais de cada ativo. Esses retornos anormais (ou excessivos) são os retornos que não podem ser explicados pela taxa de retorno do mercado. Eles são medidos como a diferença entre os retornos observados e os retornos de algum índice de referência pré-selecionado.

Utilizando essas informações, eu estimo o impacto de retornos anormais sobre os esforços em adquirir informações sobre um determinado ativo e encontro que um retorno anormal de $1 \%$ em uma semana gera um aumento de $1,3 \%$ no volume de buscas pelo ativo no Google na semana seguinte. Essa evidência é consistente com a hipótese de que investidores se informam antes de tomarem decisões de negócios no mercado acionário. Esse efeito se dissipa ao longo do tempo. Um retorno anormal absoluto de $1 \%$ leva a um aumento de por volta de 0,4\% nas buscas no Google após duas semanas, de 0,3\% após 3 semanas, de 0,1\% após 4 semanas e deixa de ser estatisticamente significativo após 5 semanas.

Em seguida, decomponho a análise em retornos anormais positivos e retornos anormais negativos, visando estudar se algum deles causa um maior impacto sobre o volume de buscas por informação. Os resultados indicam que os efeitos negativos causam um impacto maior nas buscas do que os retornos positivos. Retornos anormais negativos de $1 \%$ em uma semana geram um aumento de 1,6\% no volume de buscas na semana seguinte, enquanto retornos anormais positivos da mesma magnitude geram um aumento de $1,1 \%$ no volume de buscas. Isso significa que os retornos negativos geram volumes de buscas $0,5 \%$ maiores do que retornos positivos. 
Esse resultado é consistente com duas potenciais explicações. A primeira delas é a de que é mais fácil para um investidor realizar ganhos negociando ações subprecificadas. Para isso, basta ele comprar um ativo cujo preço está abaixo do seu valor fundamental e esperar uma reversão para patamares maiores, obtendo assim retornos positivos. A estratégia contrária exige uma implementação mais complexa. Para isso, o investidor teria que alugar a ação que ele acredita estar sobreprecificada e realizar uma venda a descoberto. Além da maior complexidade dessa operação, os custos de transação são maiores uma vez que incluem o aluguel das ações. Dessa forma, é possível que os investidores se interessem mais por ações que apresentam retornos anormais negativos. Essa interpretação é consistente com o trabalho de Shleifer e Vishny (1997) que argumenta que investidores podem escolher não aproveitar oportunidades de arbitragem por causa de fatores como custos e riscos envolvidos.

Uma segunda explicação possível é que investidores se tornam mais atentos a quedas de preços dos ativos que estão em seus portfolios do que a aumentos. O efeito disposição (Sheffrin e Statman (1985)), é a tendência por parte dos investidores de realizar ganhos cedo demais e de postergar a realização de perdas por um período muito longo. Algumas das possíveis motivações para esse comportamento incluem: (i) os investidores são mais relutantes em realizarem perdas do que ganhos (Kahnemann e Tversky (1979)); (ii) investidores que compram uma ação baseados em informações favoráveis podem vender se o preço subir, acreditando que a boa notícia foi incorporada aos preços, ou manter a ação em seu portfólio se seu preço cair, esperando que a nova informação ainda vá se refletir nos preços (Lakonishok e Smidt (1986)); e (iii) investidores podem crer que as ações que estão realizando perdas hoje irão em breve superar as ações ganhadoras de hoje e essas expectativas podem ou não ser racionais (Odean (1998)). Em todas as explicações mencionadas acima, os investidores nutrem algum tipo de expectativa (racional ou não) de que suas perdas serão revertidas, o que pode fazer com que procurem informações que sirvam de embasamento para essas expectativas. Por tenderem a realizar seus ganhos com mais facilidade, os investidores não buscam tantas informações quando os preços das ações sobem. 
Nas análises descritas acima, utilizo como medida de buscas de informação por parte dos investidores, a frequência de buscas no Google. Acredito que essa seja a medida mais adequada de atenção dos investidores para esta análise, pois quando uma pessoa faz uma busca no Google, é inquestionável que ela está dando atenção ao seu objeto de pesquisa e se empenhando ativamente em obter a informação desejada. Alguns trabalhos empíricos usam outras medidas de atenção dos investidores, como notícias (Barber e Odean (2008), Yuan (2008)), retornos e volume extremos (Barber e Odean (2008)) e despesas com publicidade ((Chemmanur e Yan (2009), Grullon et al (2004), e Lou (2008)). Todos esses trabalhos encontram uma relação entre as medidas de atenção estudadas e o comportamento dos investidores no mercado. Apesar disso, todas essas medidas são indiretas. Retornos extremos e volumes negociado acima (ou abaixo) do normal podem ser causados por fatores não relacionados com a atenção dos investidores e notícias e publicidade não garantem a atenção dos investidores, a menos que eles as leiam (Da et al (2011)).

No próximo capítulo, apresento uma breve revisão bibliográfica com uma discussão sobre artigos relevantes para este estudo. No Capítulo 3, descrevo a base de dados, as estatísticas descritivas da amostra estudada e a estratégia empírica de análise de eventos que foi utilizada neste trabalho. O Capítulo 4 mostra os resultados das análises realizadas e o Capítulo 5 apresenta os comentários finais. $\mathrm{O}$ apêndice inclui uma descrição da ferramenta Google Trends e uma explicação detalhada sobre a obtenção e o tratamento dos dados extraídos dela, além de tabelas mostrando os resultados das análises usando os dados em nível. 


\section{2. \\ Revisão Bibliográfica}

Este capítulo está dividido em duas partes. A seção 2.1 contém uma revisão teórica de artigos sobre temas relacionados à análise e aos resultados deste trabalho. Primeiramente discuto sobre artigos que serviram de motivação teórica para este trabalho, cujos temas se concentram na hipótese dos mercados eficientes e a forma como arbitradores atuam como agentes de equilíbrio no mercado. Incluo também uma revisão de trabalhos empíricos que testaram a HME e a atuação dos arbitradores no mercado. Em seguida, proponho algumas explicações teóricas para os resultados encontrados neste trabalho. A seção 2.2 mostra outros artigos que usaram dados do Google Trends em uma variedade de contextos.

\section{1.}

\section{Revisão Teórica}

Segundo Fama (1970), um mercado é considerado eficiente quando os preços dos ativos, a qualquer momento, refletem toda a informação disponível, sendo essa a premissa base da hipótese dos mercados eficientes (HME). Fama (1970) lista três formas para a HME: fraca, semi-forte e forte. Na forma fraca de eficiência de mercado, os preços dos ativos refletem todas as informações de preços e retornos passados, e é impossível para um investidor obter lucros se baseando nesse tipo de informação. A forma semi-forte tem como premissa preços que refletem toda informação pública disponível, ou seja, assim que uma informação se torna pública ela é imediatamente refletida nos preços. Já na forma forte mesmo informações privadas seriam refletidas nos preços, através de informações privilegiadas que rapidamente vazariam e seriam incorporadas aos preços. Fama (1965) testa empiricamente a forma fraca e encontra que os preços das ações seguem passeios aleatórios, o que indica que retornos passados não podem prever retornos futuros. Keown e Pinkerton (1985) encontram evidências da forma semi-forte ao estudarem os preços das ações de empresas que são alvo de uma oferta de aquisição. Ele encontra que os preços dessas ações se ajustam imediatamente ao anúncio da aquisição, o que é consistente com a forma semiforte da HME. 
Há três premissas diferentes na teoria da HME que explicam a forma como o equilíbrio é atingido pelos agentes do mercado. $\mathrm{Na}$ primeira, todos os investidores são racionais e precificam os ativos corretamente, de acordo com a informação que eles têm disponível. Na segunda, há investidores irracionais no mercado, mas como eles tomam suas decisões de investimentos de forma aleatória e não correlacionada entre si, seus negócios se cancelam sem afetar os preços dos ativos. Uma terceira alternativa é a de que há investidores que são irracionais de maneiras similares, porém investidores racionais (arbitradores) eliminam sua influência nos preços, trazendo-os de volta para os devidos patamares (Shleifer (2000)). Fama (1965) diz que com um número suficientemente alto de arbitradores no mercado, esse tipo de ajuste se daria de forma quase instantânea. Assim, a existência de arbitradores, ou investidores sofisticados, em grandes números garantiria que os preços dos ativos no mercado são sempre a melhor estimativa para o valor intrínseco deles.

Grossman e Stiglitz (1980) argumentam que se o equilíbrio competitivo é definido como uma situação em que todos os lucros provenientes de arbitragem são eliminados, não é possível que uma economia competitiva esteja sempre em equilíbrio, pois aqueles que arbitram não ganhariam nenhum retorno para se envolver na custosa atividade de arbitragem. Os arbitradores não teriam nenhum incentivo, logo não trariam os preços dos ativos para seus valores fundamentais quando ocorresse alguma variação anormal nos preços. Eles propõem um modelo de expectativas racionais onde os preços refletem as informações de indivíduos informados (arbitradores) apenas parcialmente, de forma que aqueles que despendem recursos buscando informação são recompensados por isso. No modelo, quando os indivíduos informados observam informações de que o preço de um ativo subirá, eles fazem ofertas pelo ativo fazendo com que o preço suba, e o contrário quando observam uma queda. Assim, a informação é transmitida para os indivíduos que não se informam através do sistema de preços. No modelo, há dois tipos de ativos, um livre de risco com retorno $\mathrm{R}$ e um ativo arriscado com retorno $u$, que que varia de forma aleatória a cada período e consiste de duas partes, uma observável $\theta$ e uma não observável $\varepsilon$ :

$$
\text { (1) } u=\theta+\varepsilon
$$


Há dois tipos de indivíduos, aqueles informados que observam $\theta$ e aqueles que observam apenas os preços $P, \log$ a demanda dos investidores informados depende de $\theta$ e a dos não informados de $P$. Todos os indivíduos são idênticos $e x$ ante, o que os diferencia depende se eles despendem o custo $c$ para obter informação. Sendo $x$ a oferta de ativos arriscados no mercado, e $\lambda$ o percentual de investidores informados, o equilíbrio é representado por um preço $P_{\lambda}(\theta, x)$. Os investidores não informados não observam $\theta$ nem $x$, mas o preço $P_{\lambda}(\theta, x)$ acaba revelando parte das informações dos investidores informados para os não informados. Quando a utilidade dos investidores informados é maior do que a dos investidores não informados, alguns indivíduos migram do grupo dos desinformados para o dos informados. Quanto mais indivíduos informados, menor a diferença entre as utilidades dos dois tipos de investidores, pois o sistema de preços se torna mais informativo. Os investidores informados tendem a ganhar mais retornos em suas transações que os desinformados, pois tendem a comprar ativos quando estão subprecificados e vender os sobreprecificados, mas quanto mais informativo é o sistema de preços, menores são esses retornos em relação aos agentes desinformados. O equilíbrio entre investidores informados e desinformados depende de diversos fatores, como o custo de obter informação, quão informativo é o sistema de preços e a qualidade da informação obtida pelos investidores informados.

Estudos empíricos encontram evidencias de que os investidores informados obtêm retornos maiores. Larcker e Lys (1987) testam a premissa de que existem incentivos para a aquisição de informações custosas, o que seria necessário para o equilíbrio de preços em um mercado competitivo ter eficiência informacional. Em seu estudo, eles mostram que arbitradores que obtêm informações superiores sobre os resultados de reorganizações societárias (aquisições e liquidações corporativas), adquirem participação em empresas que têm as maiores taxas de sucesso em suas reorganizações corporativas e que os arbitradores têm retornos substancialmente positivos. Mitchell e Pulvino (2001) usam uma amostra de fusões entre empresas para examinar retornos gerados por arbitragem de fusões (estratégia que tenta gerar retornos causados pela diferença entre o preço do ativo e o preço ofertado na aquisição). Os seus resultados 
indicam que esse tipo de arbitragem gera retornos acima da média dos outros investidores.

O estudo empírico feito por Seyhun (1986) usa dados de transações feitas por investidores com informações privilegiadas da Securities and Exchange Commission (SEC) e mostra evidências de que investidores com informações privilegiadas conseguem prever variações anormais nos preços das ações. Os investidores que presumidamente têm maiores informações sobre as empresas, como membros dos conselhos de administração e executivos têm maiores taxas de sucesso na previsão de variações nos preços. Jeng et al (2003) também encontram retornos anormais nos portfolios mantidos por investidores com informações privilegiadas, especialmente no curto prazo. Esses trabalhos são consistentes com a premissa de que investidores informados obtêm retornos maiores.

O objetivo deste trabalho é estudar como os investidores buscam as informações necessárias para tomar suas decisões de investimentos. Segundo os artigos discutidos acima, uma variação no preço de um ativo se deve ou a novas informações sendo disponibilizadas e incorporadas nos preços, ou a investidores não informados negociando o ativo de forma irracional. $O$ último caso proporcionaria uma oportunidade de lucros através de arbitragem para aqueles investidores que buscam informação. Analiso como o volume de buscas no Google varia com os retornos anormais e decomponho a análise em retornos positivos e negativos.

Existem algumas explicações possíveis para os impactos de choques positivos e negativos serem diferentes. A primeira delas é relacionada aos limites da arbitragem. No artigo de Schleifer e Vishny (1997) eles mostram que nem sempre arbitradores são eficazes em trazer os preços dos ativos para seus valores fundamentais, especialmente em circunstâncias extremas. Os arbitradores podem evitar se expor a posições de arbitragem mais voláteis, que apesar de oferecerem retornos atrativos, apresentam maior risco de perdas. Além dos riscos, outro fator que pode influenciar nas decisões dos arbitradores são os custos envolvidos nas transações dos arbitradores. Gromb et al (2010) apresentam em seu modelo de arbitragem custos associados a vendas a descoberto como um dos custos que afetam as posições escolhidas pelos arbitradores ao tomarem decisões de 
investimentos. Tuckman e Vila (1992, 1993) mostram que os custos de estabelecer e financiar posições previnem que os arbitradores eliminem completamente erros na precificação dos ativos, pois arbitradores apenas investem em ativos mal precificados quando isso compensa os custos incorridos com as transações. Hodges e Neyberger (1989) examinam o impacto de custos de transação nas posições dos arbitradores quando seus portfolios têm que ser rebalanceados periodicamente.

Para um arbitrador investir em uma posição de venda a descoberto, ele precisa arcar com o custo de aluguel das ações que ele acredita que estão sobreprecificadas. Esse custo adicional em si pode servir como desincentivo ao investidor. Isso somado à maior complexidade dessa transação, se comparada a uma transação simples de compra de ativos pode servir de explicação para que os retornos negativos geram maior impacto nos volumes de buscas no Google do que efeitos positivos.

Outra possível explicação é relacionada ao efeito disposição descrito por Shefrin e Statman (1985) como a tendência por parte dos investidores de manter ações que estão sofrendo perdas em seus portfolios por muito tempo, enquanto vendem ações que estão realizando ganhos cedo demais. $\mathrm{O}$ efeito disposição é uma extensão da teoria do prospecto de Kahnemann e Tversky (1979) para investimentos. A teoria do prospecto foi criada a partir de experimentos controlados e diz que quando pessoas se deparam com escolhas do tipo loteria envolvendo dois ou três resultados possíveis, elas se comportam como se maximizassem uma função utilidade em formato de $S$ (Figura 1) que é côncava na região de ganhos e convexa na região de perdas. Isso sugere aversão ao risco na área de ganhos e propensão ao risco na área de perdas, que os investidores são mais relutantes em realizar perdas do que ganhos. Uma das outras explicações sugeridas na literatura sobre efeito disposição é a de (Lakonishok e Smidt (1986)): investidores que compram uma ação baseados em informações favoráveis podem vender quando o preço dela subir, racionalmente acreditando que o preço agora reflete esta informação e podem decidir manter o ativo se o preço cair, racionalmente acreditando que a informação ainda será incorporada ao preço. Outra possibilidade é sugerida no trabalho de Odean (1998), onde ele diz que 
investidores podem decidir manter suas ações que estão realizando perdas e vender as que estão realizando ganhos porque acreditam que as ações que estão realizando perdas hoje irão em breve superar as ações ganhadoras de hoje. Essas expectativas podem ou não ser racionais.

Figura 1: Função Utilidade da Teoria do Prospecto.

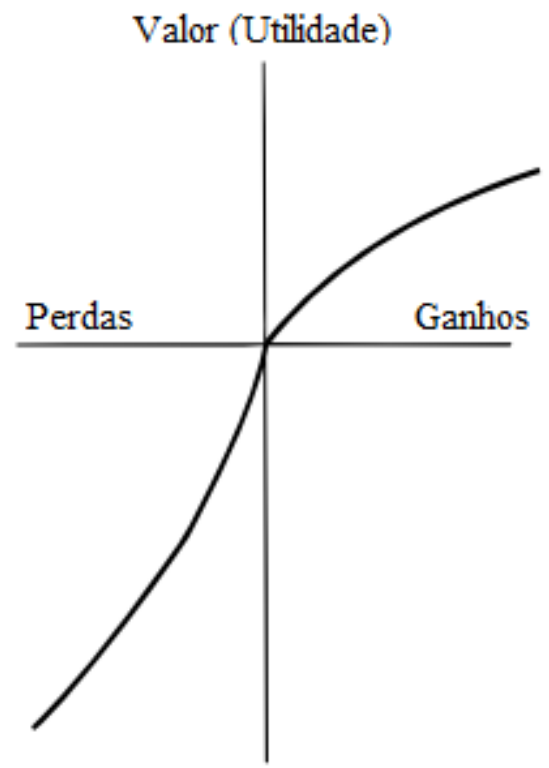

As possíveis motivações descritas acima para o efeito disposição são algumas das possibilidades sugeridas pela teoria. Nelas, os investidores esperam que os ativos que estão realizando perdas sofram uma reversão na tendência, fazendo com que eles recuperem seus investimentos, o que pode fazer com que eles busquem mais informações que fundamentem suas crenças. Ao mesmo tempo, os investidores têm maior facilidade em realizar seus ganhos, o que pode explicar um menor número de pesquisas geradas por retornos positivos.

\section{2.}

\section{Literatura Google Trends}

É crescente o número de trabalhos que usam dados de busca no Google em diversos contextos. Na medicina, por exemplo, Ginsberg et al (2009) mostram que buscas no Google podem ajudar a prever a incidência de influenza. Usando 
termos de buscas relacionados à gripe eles conseguiram estimar com precisão os níveis de influenza em diferentes regiões dos EUA.

No campo econômico, Baker e Franklin (2011) examinam a resposta do volume de buscas por empregos no Google a variações nas políticas de benefícios para desemprego, e encontram uma relação negativa entre buscas por emprego e o aumento de benefícios para desempregados. Choi e Varian (2011) usam dados de frequência de buscas no Google e fazem um sistema de previsão de dados de curtíssimo prazo. Eles mostram que dados de volume de buscas podem ser usados para prever diversos indicadores econômicos, como vendas de automóveis, pedidos de seguro desemprego, destinos de viagens e confiança do consumidor.

Drake et al (2012) investigam a relação entre demanda por informação dos investidores e anúncios de resultados de empresas. Seus resultados mostram que nas duas semanas que antecedem os anúncios de resultados de uma empresa, há um aumento substancial no volume de buscas no Google, o que continua por algum tempo após a data do anúncio. Eles também encontram que os preços de ações após anúncios de resultados têm menor variação quando o volume de buscas dos investidores é mais alto antes da divulgação dos resultados.

Da et al (2011) usam a hipótese de Barber e Odean (2008) de que investidores individuais são compradores de ações que chamam sua atenção. Eles propõem uma nova medida de atenção dos investidores usando frequência de buscas no Google, argumentando que é uma medida de atenção direta: se um indivíduo busca uma ação no Google ele inquestionavelmente está dando atenção a ela. Eles obtêm as frequências de buscas das ações que compõem o índice Russel 3000 e compara essa medida com medidas alternativas de atenção, como retornos extremos, volume de negócios e notícias, encontrando uma correlação em média positiva, porém baixa. Eles então usam um modelo VAR e encontram que a frequência de buscas costuma liderar as outras medidas de atenção, indicando que investidores começam a prestar atenção a uma ação antes de um evento noticiado. Depois, os autores testam se os investidores de fato compram as ações que mais atraem sua atenção. Os resultados encontrados no trabalho indicam que um aumento no volume de buscas no Google pelas ações analisadas no trabalho representa um aumento nos seus preços nas semanas seguintes. Ao realizar os 
testes com empresas que estão realizando uma oferta pública inicial (IPO), eles encontram evidências de que a frequência de buscas no Google está relacionada aos retornos de primeiro dia de um IPO, e a subsequente reversão nos seus retornos. 


\section{3. \\ Análise de Dados e Metodologia Empírica}

3.1.

Base de Dados

Neste trabalho foram analisados dados de volume de buscas no Google e de retornos anormais de 58 empresas. Os dados de volume de buscas no Google foram obtidos através da ferramenta Google Trends, que fornece dados de frequência de buscas no Google dos termos de interesse. Os dados foram coletados manualmente no site do Google Trends (https://trends.google.com.br/) ${ }^{1}$. Com isso, foi criada uma base de dados com o volume de buscas semanal das empresas estudadas entre o período de janeiro de 2007 e dezembro de 2016.

As empresas estudadas são aquelas cujas ações compunham o índice Ibovespa em dezembro de 2016. Um dos critérios de inclusão de empresas no índice Ibovespa é que no período de 12 meses anteriores à formação da carteira, as ações que compõem o índice representem, em conjunto, $85 \%$ de todos os negócios da Bovespa. Dessa forma, as ações que compõe o índice têm alta representatividade no mercado nacional, sendo elas as mais líquidas, o que garante que os dados de buscas no Google Trends tragam mais resultados diferentes de zero. ${ }^{2}$

As buscas no Google representam uma parcela relevante dos meios que os usuários de Internet usam para buscar informações. Em março de 2014, o Google era o site de buscas mais utilizado no país, representando $96,5 \%$ do total de buscas realizadas $^{3}$.

Para realizar as buscas no Google Trends, foram usados os tickers de cada ação, da mesma forma que no trabalho de Da et al (2011). O uso dos tickers em vez dos nomes das empresas foi feito para assegurar que as buscas estivessem sendo feitas por investidores buscando informações financeiras sobre a empresa.

\footnotetext{
${ }^{1}$ Para mais informações sobre o Google Trends e sobre a obtenção e tratamento dos dados, ver Apêndices A e B

${ }^{2}$ Conforme detalhado no Apêndice A, o Google Trends só fornece dados de termos com volume considerável de buscas

3 Pesquisa realizada pela Serasa Experian com dados da ferramenta Hitwise (http://noticias.serasaexperian.com.br/blog/2014/04/23/google-brasil-lidera-buscas-na-internet-emmarco-de-acordo-com-dados-da-hitwise/)
} 
Usar os nomes das empresas poderia trazer resultados de pessoas buscando informações que não são relacionadas a investimentos. Por exemplo, uma pessoa poderia buscar a palavra "Natura" com a intenção de comprar os produtos da empresa. Algumas buscas seriam ambíguas, como "Rumo" e "Vale" que têm outros significados, além de serem nomes de empresas.

A fonte de informação das ações que compunham o Ibovespa em dezembro de 2016 foi o site da BM\&F Bovespa. As séries de dados de preços das ações e do índice Ibovespa, usadas para a construção da série de retornos anormais, foram obtidas na Bloomberg, assim como as séries de volume negociado dos papéis.

\section{2 . \\ Estatísticas descritivas}

A Tabela I mostra as estatísticas descritivas dos dados de frequência de buscas semanal no Google no período analisado, que foi de janeiro de 2007 a dezembro de 2016.

Apesar dos anos de 2007 e 2008 apresentarem resultados maiores de média, mediana e total de buscas do que os anos subsequentes de 2009 a 2014, a evolução crescente dos valores de primeiro quartil e decrescente do percentual de buscas iguais a zero indicam que as buscas se tornaram mais frequentes entre as ações analisadas ao longo dos anos. Os anos de 2015 e 2016 apresentaram estatísticas expressivamente maiores do que a dos anos anteriores.

O gráfico mostrado na Figura 2 exibe o comportamento da média de buscas ao longo do período analisado. Esse resultado pode estar relacionado ao aumento no número de dispositivos móveis com conexão à internet nos últimos anos, conforme pesquisa realizada pela FGV-SP (Meirelles (2016), mostrado na Figura 3 (Meirelles (2016).

Algumas das empresas estudadas neste trabalho realizaram IPOs ao longo do período estudado. A coluna de número médio de ações, na Tabela I, mostra a evolução do número médio de ações estudadas por anos. No período inicial, de 2007, havia 42 papéis sendo analisados. No final de 2013, o número chegou a 58. 


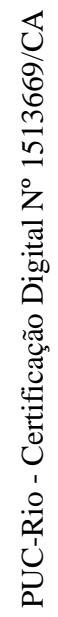

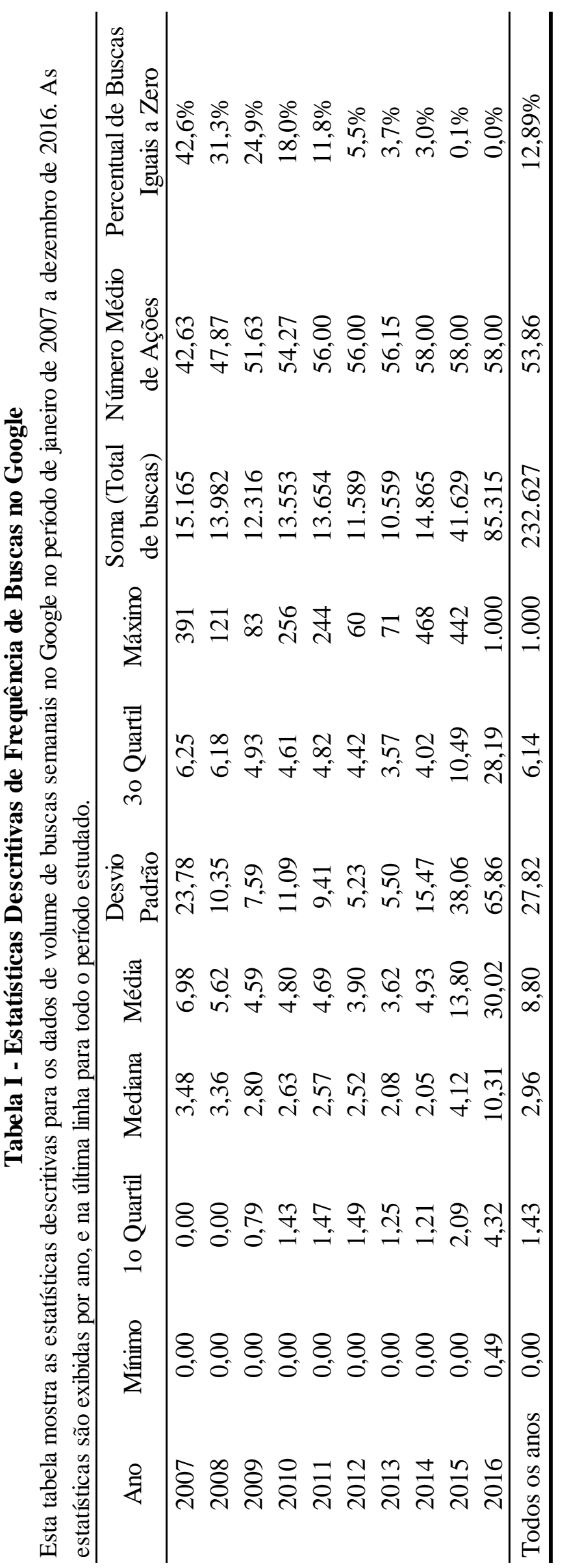


Figura 2: Média dos dados de volume de buscas no Google ao longo do período estudado de janeiro de 2007 a dezembro de 2016 .

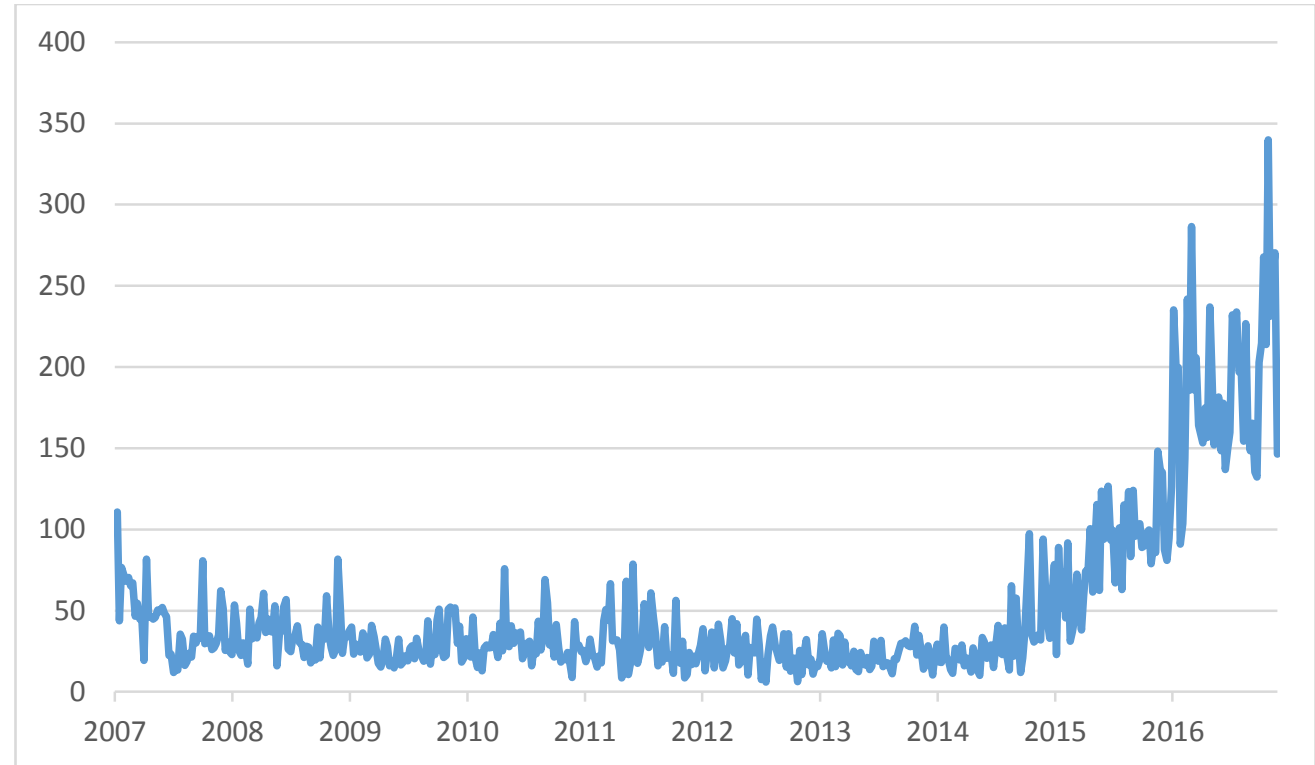

Figura 3: Número de dispositivos móveis wireless conectáveis à Internet em uso no Brasil.

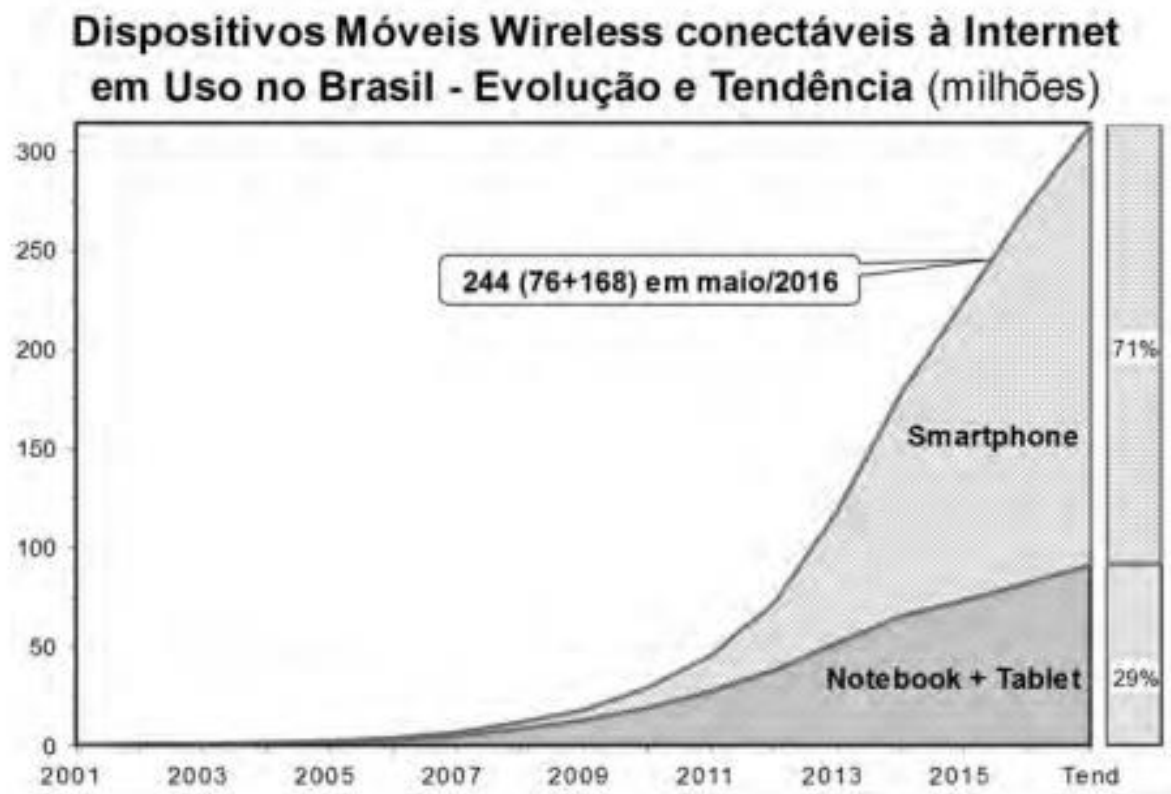


As empresas estudadas estão divididas entre nove setores, conforme Tabela II.

Tabela II: Número de Empresas por Setor

\begin{tabular}{|l|c|}
\hline Setor & Número de Empresas \\
\hline Consumo e Varejo & 10 \\
\hline Serviços & 5 \\
\hline Energia e Saneamento & 8 \\
\hline Financeiro & 10 \\
\hline Imobiliário e Construção & 4 \\
\hline Industrial & 2 \\
\hline Commodities & 13 \\
\hline Telecomunicações & 2 \\
\hline Transporte e Logística & 4 \\
\hline
\end{tabular}

\section{3. \\ Metodologia Empírica}

Neste trabalho, uso como estratégia empírica a metodologia de estudos de eventos, que foi introduzida por Fama et al (1969). Em estudos de eventos, o objetivo é analisar se retornos anormais ou excessivos acompanham eventos específicos, sendo os retornos anormais a diferença entre o retorno observado e os retornos de um índice de referência. Os retornos anormais das ações neste trabalho foram calculados como a diferença entre os retornos observados das ações e as variações do índice Ibovespa, que foi usado como referência para os retornos esperados no mercado brasileiro.

$$
\mathrm{AR}_{\mathrm{it}}=\mathrm{R}_{\mathrm{it}}-\mathrm{R}_{\mathrm{mt}}
$$

Onde:

$\mathrm{AR}_{\mathrm{it}}=$ Retorno anormal da ação i na semana $\mathrm{t}$

$\mathrm{R}_{\mathrm{it}}=$ Retorno observado da ação i na semana $\mathrm{t}$

$\mathrm{R}_{\mathrm{mt}}=$ Retorno do índice Ibovespa na semana $\mathrm{t}$ 


\section{4. \\ Resultados}

Nesta seção, mostro que os investidores buscam ativamente informações sobre as empresas ao perceberem variações nos retornos anormais das mesmas. Para isso, analiso o efeito que uma variação nos retornos anormais absolutos de uma ação em uma dada semana gera no logaritmo do volume de buscas por ela no Google na semana seguinte.

Primeiro, faço uma análise através de uma regressão linear entre o logaritmo das buscas no Google em $\mathrm{t}+1$ e os retornos anormais absolutos das ações em t, conforme abaixo:

$$
\log \mathrm{g}_{\mathrm{t}+1}^{\mathrm{i}}=\alpha+\beta\left|\mathrm{R}_{\mathrm{t}}^{\mathrm{i}}\right|+\mu_{\mathrm{t}}^{\mathrm{i}}(1)
$$

Onde:

$\mathrm{g}_{\mathrm{t}+1}^{\mathrm{i}}=$ Buscas no Google da ação i na semana $\mathrm{t}+1$

$|\mathrm{Rit}|=$ valor absoluto dos retornos anormais da ação i na semana $\mathrm{t}$

$\mu_{t}^{i}=$ Erro padrão

A mesma relação é testada usando diferentes variáveis de controle. A primeira variável de controle usada são nove dummies de ano (para os anos de 2008 a 2016). Na terceira especificação do modelo, incluo nove variáveis dummy de indústrias. As indústrias consideradas no modelo são aquelas detalhadas na Tabela II.

Além das variáveis dummy mencionadas acima, outra variável de interesse é o volume semanal, em Reais, negociado de cada ação estudada. Assim como os retornos extremos, o volume negociado pode ser considerada uma proxy para variável de atenção dos investidores e poderia causar o interesse dos investidores em buscar mais informações sobre as empresas negociadas em um volume acima do normal. Dessa forma, incluo o volume negociado como variável de controle na análise. Por fim, faço uma regressão incluindo todas as variáveis de controle citadas, conforme a regressão especificada abaixo. 
$\log \mathrm{g}_{\mathrm{t}+1}^{\mathrm{i}}=\alpha+\beta_{1}\left|\mathrm{R}_{\mathrm{t}}^{\mathrm{i}}\right|+\beta 2$ Ano $_{\mathrm{t}}^{\mathrm{i}}+\beta 3$ Indústria $_{\mathrm{t}}^{\mathrm{i}}+\beta 4$ Volume $_{\mathrm{t}}^{\mathrm{i}}+\mu_{\mathrm{t}} \mathrm{i}_{\mathrm{t}}(2)$

Onde:

$\mathrm{g}_{\mathrm{t}+1}^{\mathrm{i}}=$ Buscas no Google da ação i na semana $\mathrm{t}+1$

$\left|R_{t}^{i}\right|=$ valor absoluto dos retornos anormais da ação i na semana $t$

$\operatorname{Ano}_{\mathrm{t}}^{\mathrm{i}}=$ Dummies dos anos de 2008 a 2016

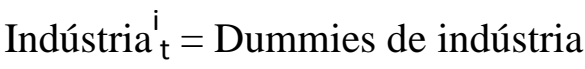

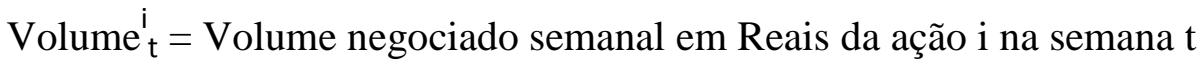

$\mu_{t}^{i}=$ Erro padrão

Segundo Petersen (2009), estudos que usam dados em painel em finanças costumam apresentar correlação serial dos erros padrão entre empresas e entre os diferentes períodos analisados, fazendo com que a análise de Mínimos Quadrados Ordinários (MQO) seja viesada. As estatísticas de teste das análises apresentadas nesta seção são calculadas usando o método de Newey-West para a correção de correlação serial, sendo esse um dos métodos apresentados por Petersen (2009).

$\mathrm{Na}$ Tabela III, os resultados dessa análise indicam uma relação estatisticamente significativa e positiva entre as buscas no Google dos tickers das ações em uma dada semana e os retornos anormais das ações na semana anterior, com p-valores menores que $1 \%$ para a maioria das especificações.

Os resultados encontrados mostram que uma variação absoluta de $1 \%$ nos retornos de uma ação leva a um aumento nas buscas pelo seu ticker de aproximadamente $1,7 \%$. Ao incluir as variáveis de controle, a relação mantém uma relação positiva e significante, no entanto, escala um pouco menor. $\mathrm{Na}$ especificação que inclui todas as variáveis de controle, os resultados indicam um aumento de 1,3\% nas buscas no Google na semana seguinte a um aumento de $1 \%$ nos retornos absolutos das ações. O fato de que os resultados não se alteram de forma muito significativa quando são incluídas variáveis de controle na regressão é um indício de que o método que está sendo utilizado é adequado, e de que as variações no volume de buscas não estão sendo causadas por alguma outra variável que não os retornos anormais. Os resultados dessa análise usando as 
variáveis do Google em nível, em vez de em logaritmo, podem ser vistos na Tabela VI do Apêndice C. Eles mostram que, na especificação com todas as variáveis de controle, uma variação absoluta de $1 \%$ nos retornos anormais gera um aumento nas buscas no Google de 0,769 , que é equivalente a $26 \%$ da mediana dos dados de busca observados, $9 \%$ da média e aproximadamente $13 \%$ do terceiro quartil.

Além do impacto dos retornos anormais, é encontrado também um impacto significativo de variações no volume sobre as buscas no Google. Os resultados mostram que um aumento de $\mathrm{R} \$ 1$ milhão no volume negociado de uma ação aumenta o volume de buscas no Google em $0,1 \%$. O resultado pode estar relacionado ao fato de que alterações no volume estão associadas a variações nos retornos e também a outros eventos que chamam a atenção do mercado, o que leva os investidores a irem atrás de novas informações.

Os resultados da Tabela III confirmam a hipótese discutida neste trabalho, de que os investidores buscam ativamente informações sobre as empresas que apresentam retornos anormais. Isso é um indício de que eles buscam entender se alguma alteração nos fundamentos da empresa justifica a alteração no preço, antes de tomar a decisão de comprar ou vender a ação. 


\section{Tabela III -}

\section{Impacto dos Retornos Anormais no Volume de Buscas no Google}

A coluna (1) mostra a regressão linear entre o logaritmo das buscas no Google em t+1 e o valor absoluto dos retornos anormais das ações em t, usando dados semanais que abrangem o período de janeiro de 2007 a dezembro de 2016. As estatísticas de teste são calculadas usando o método Newey-West para correção de autocorrelação serial. A coluna (2) mostra a mesma regressão adicionando dummies de ano, a (3) usando dummies de indústria, a (4) usando o volume em Reais negociado das ações no período $t$ e a (5) mostra a regressão usando todas as variáveis das colunas (2) a (4). Os resultados abaixo apresentam o coeficiente da regressão e o erro padrão, entre parênteses. *, ** e *** representam níveis de significância de $10 \%, 5 \%$ e 1\%, respectivamente.

\begin{tabular}{|c|c|c|c|c|c|}
\hline \multicolumn{6}{|c|}{ Variável Dependente: Logaritmo das Buscas no Google } \\
\hline & (1) & (2) & (3) & (4) & (5) \\
\hline Retornos & $0,017 * * *$ & $0,010 * *$ & $0,016^{* * *}$ & $0,023 * * *$ & $0,013 * * *$ \\
\hline anormais & $(0,005)$ & $(0,003)$ & $(0,005)$ & $(0,003)$ & $(0,002)$ \\
\hline Volume & Não & Não & Não & $\begin{array}{c}0,002 * * * \\
(0,0001)\end{array}$ & $\begin{array}{c}0,001 * * * \\
(0,0001)\end{array}$ \\
\hline $\begin{array}{l}\text { Dummies de } \\
\text { ano }\end{array}$ & Não & Sim & Não & Não & Sim \\
\hline Indústrias & Não & Não & Sim & Não & Sim \\
\hline $\mathrm{R}^{2}$ & 0,010 & 0,206 & 0,120 & 0,252 & 0,465 \\
\hline
\end{tabular}


Verifico se o efeito positivo dos retornos anormais no volume de buscas no Google persiste por períodos maiores do que uma semana. A Tabela IV mostra os resultados de regressões usando o mesmo modelo da Equação (2), usando buscas no Google até seis semanas a frente dos retornos anormais.

\section{Tabela IV -}

\section{Persistência dos Resultados}

A coluna (1) mostra a regressão linear entre o logaritmo das buscas no Google em $t+j$ e o valor absoluto dos retornos anormais das ações em $\mathrm{t}$, usando dados semanais que abrangem o período de janeiro de 2007 a dezembro de 2016. As estatísticas de teste são calculadas usando o método Newey-West para correção de autocorrelação serial. A coluna (2) mostra a mesma regressão adicionando dummies de ano, a (3) usando dummies de indústria, a (4) usando o volume em Reais negociado das ações no período $t$ e a (5) mostra a regressão usando todas as variáveis das colunas (2) a (4). Os resultados abaixo apresentam o coeficiente da regressão e o erro padrão, entre parênteses. *, ** e *** representam níveis de significância de $10 \%, 5 \%$ e 1\%, respectivamente.

\begin{tabular}{lccccc}
\hline & $(1)$ & $(2)$ & $(3)$ & $(4)$ & $(5)$ \\
& $j=$ & $j=$ & $j=$ & $j=$ & $j=$ \\
& $\begin{array}{c}\text { Períodos a } \\
\text { frente }\end{array}$ & $\begin{array}{c}3 \text { Períodos a } \\
\text { frente }\end{array}$ & $\begin{array}{c}4 \text { Períodos a } \\
\text { frente }\end{array}$ & $\begin{array}{c}5 \text { Períodos a } \\
\text { frente }\end{array}$ & $\begin{array}{c}\text { 6 Períodos } \\
\text { a frente }\end{array}$ \\
\hline Retornos & $0,004 * * *$ & $0,003 * * *$ & $0,001 *$ & $-0,0002$ & $-0,0003$ \\
anormais & $(0,001)$ & $(0,001)$ & $(0,001)$ & $(0,0001)$ & $(0,0001)$ \\
Volume & $0,0004 * * *$ & $0,0004 * * *$ & $0,0004 * * *$ & $0,0004 * * *$ & $0,0004 * * *$ \\
Dummies de ano & $(0,00003)$ & $(0,00003)$ & $(0,00003)$ & $(0,00003)$ & $(0,00003)$ \\
Indústrias & Sim & Sim & Sim & Sim & Sim \\
$\mathrm{R}^{2}$ & Sim & Sim & Sim & Sim & Sim \\
& 0,064 & 0,065 & 0,064 & 0,064 & 0,064 \\
\hline
\end{tabular}


Os resultados mostram que há uma persistência nos impactos dos retornos anormais nas buscas no Google de até três semanas, apesar de em proporções bem menores. Os impactos dos retornos na semana $t$ no volume de buscas em $t+2$ podem ser vistos na coluna (1) da Tabela IV: um aumento de 1\% nos retornos anormais em $\mathrm{t}$ gera um aumento de $0,4 \%$ nas buscas no Google em t+2. Os resultados persistem até a semana $t+3$. A coluna (2) da Tabela III mostra que há um efeito de $0,3 \%$ nas buscas no Google em $\mathrm{t}+3$ após retornos anormais de $1 \%$ em $\mathrm{t}$ e de $0,1 \%$ na regressão com mais um período a frente. Depois disso, as regressões param de apresentar significância estatística, o que sugere que os efeitos dos retornos anormais sobre as buscas no Google só persistem por três semanas. Os resultados acima são compatíveis com a premissa da HME que diz que os arbitradores agem de forma quase imediata em suas transações (Fama (1965)).

Figura 4: Persistência dos efeitos dos retornos anormais no volume de buscas no Google

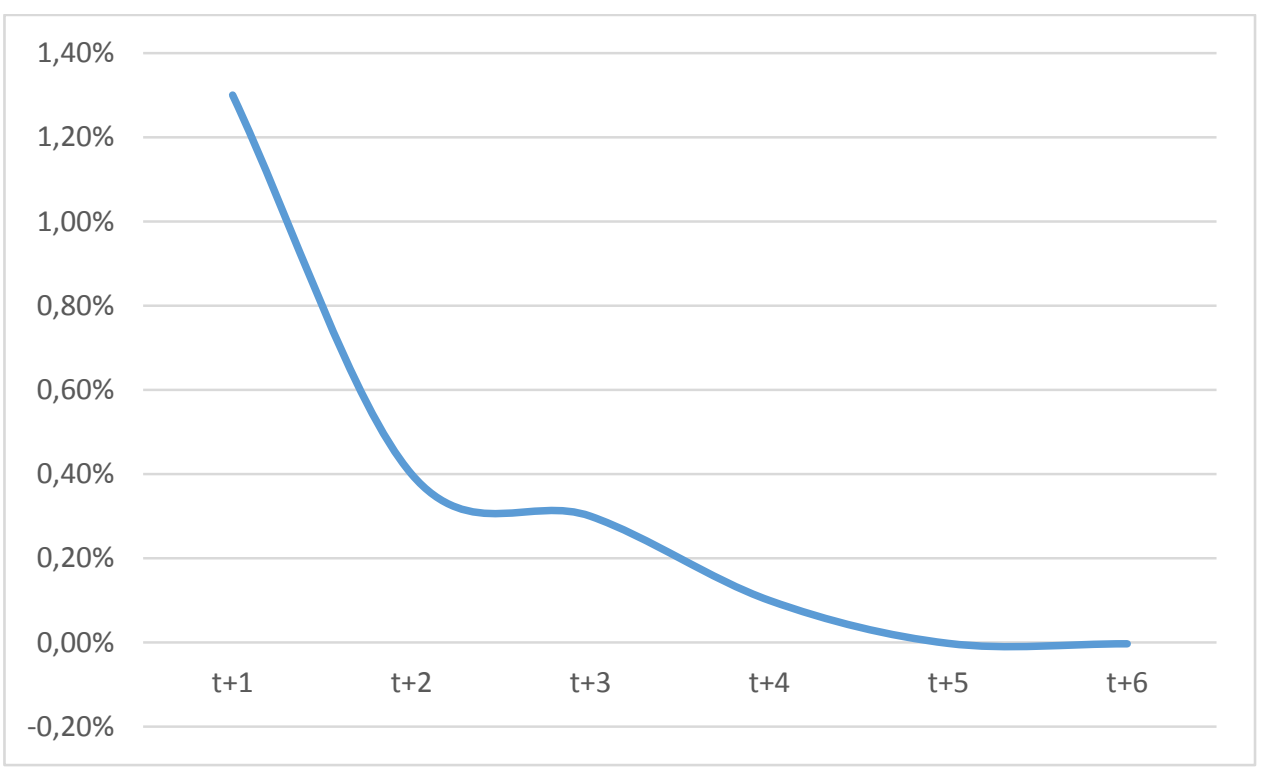


A próxima análise foi buscar entender se retornos anormais positivos geram mais buscas no Google do que os retornos negativos, ou vice-versa. Os resultados dessa análise estão na Tabela V, e o modelo usado (na coluna (5) da Tabela V) é o especificado abaixo:

$\log g_{t+1}^{i}=\alpha+\beta_{1} \operatorname{RNeg}_{t}^{i}+\beta_{1} \operatorname{RPos}_{t}^{i}+\beta_{3} \operatorname{Ano}_{t}^{i}+\beta_{4}$ Indústria $_{t}^{i}+\beta_{5} \operatorname{Volume}_{t}^{i}+\mu_{t}^{i}$ (3)

Onde:

$\mathrm{g}_{\mathrm{t}+1}^{\mathrm{i}}=$ Buscas no Google da ação i na semana $\mathrm{t}+1$

$\mathrm{RNeg}_{\mathrm{t}}^{\mathrm{i}}=$ retornos anormais negativos da ação i na semana $\mathrm{t}$

$\operatorname{RPos}_{t}^{i}=$ retornos anormais positivos da ação i n semana $t$

Ano $_{t}^{i}=$ Dummies dos anos de 2008 a 2016

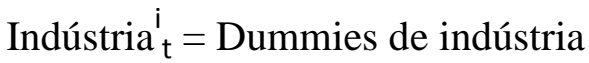

Volume $_{t}^{i}=$ Volume negociado semanal em Reais da ação i na semana $t$

$\mu^{i}=$ Erro padrão

Os resultados mostram que os retornos negativos geram mais buscas por parte dos investidores do que os positivos. Enquanto, na especificação definida na equação (3), uma queda equivalente a $1 \%$ dos retornos anormais gera um aumento de 1,6\% no índice de buscas no Google, um aumento nos retornos anormais na mesma proporção gera um aumento de $1,1 \%$. Ou seja, os retornos negativos geram um impacto nas buscas no Google $0,5 \%$ maior do que os retornos positivos.

Como descrito anteriormente, esses resultados têm algumas explicações possíveis. Uma delas é que, ao perceber retornos negativos, os investidores percebem uma possível oportunidade de comprar um ativo com o preço abaixo do seu valor real e realizar ganhos positivos quando a ação voltar ao seu preço justo, o que os leva a buscar informações sobre ela. Apesar de ser possível realizar ganhos com posições de venda a descoberto de ações com expectativa de queda de preços, esse processo envolve mais custos, como o de aluguel das ações a serem vendidas e também é mais complexo. Essas potenciais limitações à arbitragem 
podem fazer com que os investidores em geral se interessem mais por oportunidades de compra de ativos que estão abaixo do seu valor fundamental. Isso é consistente com o trabalho de Shleifer e Vishny (1997) que diz que arbitradores muitas vezes evitam assumir posições mais custosas e arriscadas, assim como com outros trabalhos que apresentam modelos de arbitragem onde os custos de transação impactam o comportamento dos arbitradores (Gromb et al (2010), Tuckman e Vila (1992, 1993) e Hodges e Neyberger (1989)).

\section{Tabela V-}

\section{Impacto dos Retornos Anormais no Volume de Buscas no Google: Decompondo Retornos em Positivos e Negativos}

A coluna (1) mostra a regressão linear entre o logaritmo das buscas no Google em t+1 e o valor dos retornos anormais positivos das ações em $\mathrm{t} e$ dos retornos anormais negativos das ações em t, usando dados semanais que abrangem o período de janeiro de 2007 a dezembro de 2016. As estatísticas de teste são calculadas usando o método Newey-West para correção de autocorrelação serial. A coluna (2) mostra a mesma regressão adicionando dummies de ano, a (3) usando dummies de indústria, a (4) usando o volume em Reais negociado das ações no período t e a (5) mostra a regressão usando todas as variáveis das colunas (2) a (4). Os resultados abaixo apresentam o coeficiente da regressão e o erro padrão, entre parênteses. *, ** e *** representam níveis de significância de $10 \%, 5 \%$ e $1 \%$, respectivamente.

Variável Dependente: Logaritmo das Buscas no Google

(1)

(2)

(3)

(4)

(5)

\begin{tabular}{lccccc}
\hline Retornos & $-0,024 * * *$ & $-0,014 * * *$ & $-0,023 * * *$ & $-0,028^{* * *}$ & $-0,016 * * *$ \\
negativos & $(0,004)$ & $(0,003)$ & $(0,004)$ & $(0,003)$ & $(0,002)$ \\
Retornos & $0,013 * * *$ & $0,009 * *$ & $0,013 * *$ & $0,018 * * *$ & $0,011 * * *$ \\
positivos & $(0,005)$ & $(0,003)$ & $(0,005)$ & $(0,003)$ & $(0,002)$ \\
Volume & Não & Não & Não & $0,002 * * *$ & $0,001 * * *$ \\
Dummies de & Não & Sim & Não & Não & Sim \\
ano & Não & Não & Sim & Não & Sim \\
Indústrias & 0,013 & 0,208 & 0,122 & 0,253 & 0,465 \\
$\mathrm{R}^{2}$ & & & & &
\end{tabular}


Outro possível motivo para os retornos negativos gerarem maior impacto no volume de buscas é relacionado ao efeito disposição (Shefrin e Statman (1985)), que é a tendência por parte dos investidores de manter em suas carteiras os ativos que estão em queda, e ao mesmo tempo realizar rapidamente os ganhos dos ativos que estão em alta. Isso pode ser causado por uma aversão menor ao risco em situações de perdas (Kahnemann e Tversky (1979)) ou porque os investidores acreditam que haverá uma reversão na tendência de perdas, por motivos racionais ou não (Lakonishok e Smidt (1986), Odean (1998)).Enquanto os investidores vendem as ações que estão realizando ganhos sem ponderar muito sobre isso, eles podem estar buscando indícios que as ações de seu portfolio que estão em queda vão sofrer uma reversão nessa tendência, o que serviria de justificativa para a sua atitude de não vender os ativos perdedores. 


\section{5. \\ Conclusão}

Segundo a Teoria dos Mercados Eficientes, os preços dos ativos sempre refletem toda informação disponível no mercado e qualquer ação mal precificada tem seu preço rapidamente corrigido através da ação de arbitradores. O objetivo deste trabalho é entender se os investidores, ao se depararem com ações que apresentam variações em seus preços, se informam sobre elas antes de tomar a decisão de comprar ou vender aquele ativo. Isso seria um indício de que eles buscam descobrir se as variações nos preços são causadas por novas informações disponibilizadas no mercado, que alterariam os fundamentos da empresa, justificando a variação nos preços, ou se eles teriam encontrado uma oportunidade de arbitragem. Como medida para o volume de busca por informação, uso a dados de frequência de buscas no Google. Foram coletados dados semanais de frequência de buscas na ferramenta Google Trends, dos tickers das 58 empresas que compunham o índica Ibovespa em dezembro de 2016. O período estudado foi entre janeiro de 2007 e dezembro de 2016.

Estudo a hipótese de que os investidores buscam ativamente informações sobre as empresas após perceberem variações em seus preços. Para isso, testo o impacto dos retornos anormais, em dada semana, sobre o volume de buscas no Google na semana seguinte. Os resultados das regressões são positivos e estatisticamente significantes em todas especificações testadas com diferentes variáveis de controle.

Analiso a persistência desses resultados, usando defasagens maiores nos dados de retornos anormais. Os resultados indicam uma persistência de até três semanas nos efeitos dos retornos anormais sobre as buscas no Google, em menor escala.

Por último, realizo o mesmo teste separando os dados de retornos anormais em retornos anormais positivos e retornos anormais negativos. Os resultados mostram que tanto os retornos negativos quanto positivos levam a um aumento no volume de buscas no Google, mas o impacto de retornos negativos no volume de buscas é maior do que o dos retornos positivos. Uma possível justificativa para 
esses resultados seria a de que a operação de vender a descoberto uma ação com preços maiores do que o esperado é mais custosa e complexa do que a de compra de uma ação subprecificada, o que é consistente com a teoria de limitações à arbitragem. Outra possível explicação é que os investidores tendem a segurar em seus portfolios ações que estão perdendo valor, enquanto vendem rapidamente ações que estão proporcionando ganhos, o que é chamado de efeito disposição. Como os investidores realizam seus ganhos rapidamente, talvez se preocupem menos em buscar informações sobre as ações antes de vende-las. Ao mesmo tempo, buscam mais informações sobre as ações que estão perdendo valor, procurando boas notícias que justifiquem a manutenção desses ativos em seus portfolios. 


\section{6. \\ Referências Bibliográficas}

BAKER, S.; FRADKIN, A. What Drives Job Search? Evidence from Google

Search Data. Technical report, Stanford University, 2011.

BARBER, B., AND ODEAN T.; All That Glitters: The Effect of Attention and News on the Buying Behavior of Individual and Institutional Investors,

Review of Financial Studies 21, 785-818, 2008.

BROWN, S.; WARNER, J. Using Daily Stock Returns - The Case of Event Studies. Journal of Financial Economics, 14, 3 - 31, 1985.

CHEMMANUR, T.; YAN, A. Advertising, Attention, and Stock Returns, Working paper, Boston College and Fordham University, 2009.

CHOI, H.; VARIAN, H. Predicting the Present with Google Trends. Working Paper, Google Inc., 2009.

DA, Z.; ENGELBERG, J.; GAO, P. In Search of Attention. The Journal of Finance, Vol. 66, No. 5, 1461 - 1499, 2011.

DRAKE, M.; ROULSTONE, D.; THORNOCK, J. Investor Information Demand: Evidence from Google Searches Around Earnings Announcements. Journal of Accounting Research, Vol. 50, No. 4, 1001 - 1040, 2012.

FAMA, E. The Behavior of Stock-Market Prices. Journal of Business, Volume 38, Issue 1, $34-105,1965$.

FAMA, E.; Efficient Capital Markets: A Review of Theory and Empirical Work. The Journal of Finance, Volume 25, No. 2, 383 - 417, 1970.

FAMA, E.; FISHER, L.; JENSEN, M.; ROLL, R. The Adjustment of Stock Prices to New Information. International Economic Review, Volume 10, No. 1, $1-21,1969$.

GINSBERG, J.; MOHEBBI, M.; PATEL, R.; BRAMMER, L.; SMOLINSKI, M.; BRILLIANT, L. Detecting Influenza Epidemics Using Search Engine Query Data. Nature 457, 1012-1014, 2009.

GROMB, D.; VAYANOS, D. Limits of Arbitrage: The State of Theory. NBER Working Paper No. 15821, 2010. 
GROSSMAN, S.; STIGLITZ, J. On the Impossibility of Informationally Efficient Markets. The American Economic Review, Vol. 70, No. 3, 393-408, 1980.

GRULLON, G.; KANATAS, G.; WESTON, J. Advertising, Breath of Ownership, and liquidity. Review of Financial Studies 17, 439-461, 2004.

HODGES, S.; NEUBERGER, A. Optimal Replication of Contingent Claims Under Trasaction Costs. The Review of Futures Markets, Vol. 8, No. 2, 117 138, 1989.

JENG, L; METRICK, A.; ZECKHAUSER, R. Estimating the Returns of Insider Trading: A Performance-Evaluation Perspective. The Review of Economics and Staistics, Vol. 85, No. 2, 453 - 471, 2003.

KAHnEMAn, D.; TVERSKY, A. Prospect Theory: An Analysis of Decision Under Risk. Econometrica (pre-1986); 47, 2; ABI/INFORM Global pg. 263, 1979.

KEOWN, A; PINKERTON, J. Merger Announcements and Insider Trading Activity: An Empirical Investigation. The Journal of Finance, Vol. 36, No. 4, $855-869,1981$.

LAKONISHOK, J.; SMIDT, S. Volume for Winners and Losers: Taxation and Other Motives for Stock Trading. The Journal of Finance, 951-974, 1986.

LARCKER, D.; LYS, T. An empirical analysis of the incentives to engage in costly information acquisition: The case of risk arbitrage. Journal of Financial Economics, Vol. 18, No. 1, 111-126, 1987.

LOU, D. Attracting Investor Attention Through Advertising. Working paper, London School of Economics and Political Science, 2008.

MEIRELLES, F. Administração e Uso da TI - Tecnologia de Informação nas Empresas. FGV EAESP, $27^{\mathrm{a}}$ Edição, 2016.

MITCHELL, M.; PULVINO, T. Characteristics of Risk and Return in Risk Arbitrage. The Journal of Finance, Vol. 56, No. 6, 2135 - 2175, 2001.

ODEAN, T. Are Investors Reluctant to Realize Their Losses? The Journal of Finance, Vol. 53, No. 5, 1775 - 1798, 1998.

PETERSEN, M. Estimating Standard Errors in Finance Panel Data Sets: Comparing Approaches. The Review of Financial Studies, Volume 22, No. 1, 435-480, 2009. 
SEYHUN, H. Insiders' profits, costs of trading, and market efficiency. Journal of Financial Economics, Vol. 16, No. 2, 189 - 212, 1986,

SHEFRIN H.; STATMAN, M. The Disposition to Sell Winners Too Early and Ride Losers Too Long: Theory and Evidence. The Journal of Finance, Vol. 40, No. 3, 777 - 790, 1985.

SHLEIFER A.; VISHNY R. The Limits of Arbitrage. The Journal of Finance, Vol. 52, No. 1, 35-55, 1997.

SHLEIFER, A.; Inefficient Markets: An Introduction to Behavioral Finance. Oxford: Oxford University Press, 2000.

TUCKMAN, B.; VILA, J. Arbitrage with holding costs: a utility-based approach. The Journal of Finance, Vol. 47, No. 4, 1283-1302, 1992.

TUCKMAN, B.; VILA, J. Holding costs and equilibrium arbitrage. Working paper, Massachusetts Institute of Technology, 1993.

YUAN, Y. Attention and trading. Working paper, University of Iowa, 2008. 


\section{APÊNDICE}

\section{A. Google Trends - A Ferramenta}

O Google disponibiliza dados de frequência de buscas feitas no site através do Google Trends (https://trends.google.com.br). Os dados de buscas são apresentados em uma escala comparativa com as buscas daquele termo no período analisado, onde o ponto máximo de popularidade de buscas assume o valor normalizado de 100. As buscas podem ser filtradas por período e por região (país ou cidade). É possível filtrar as buscas por pesquisas gerais, pesquisas de notícias, pesquisas de imagens, vídeos e compras. Também é possível fazer um filtro por categoria (alguns exemplos são "Ciências, "Compras" e "Esportes"). Devido a questões de proteção de privacidade, apenas termos com volume considerável de buscas são acompanhados.

Ao realizar uma busca por um termo no Google Trends, o site retorna os seguintes resultados: (i) interesse ao longo do tempo, que é o gráfico com a frequência de buscas ao longo do período selecionado, (ii) interesses por região, mostrando em quais regiões aquele termo é mais buscado e (iii) tópicos e consultas relacionadas, mostrando os tópicos e consultas pesquisados por usuários também que fizeram buscas pelo termo escolhido. Por exemplo, o termo "IBOV", símbolo do índice Ibovespa na bolsa de valores, mostra o Brasil como região de maior popularidade, "Ibovespa - Índice de Mercado" como principal tópico relacionado e "petr4" ticker da Petrobrás na bolsa de valores, como principal consulta relacionada, conforme a Figura 4. Todos os resultados listados acima podem ser baixados em arquivos no formato CSV.

O Google Trends disponibiliza dados de frequência de buscas a partir de janeiro de 2004. O período de busca mais longo a ser pesquisado é de janeiro de 2004 até o presente, e o mais curto é o volume de buscas na última hora. A frequência dos resultados depende do período pesquisado. Ao pesquisar o volume de buscas em um período de até um dia, os resultados mostram a buscas por minuto. Para períodos de uma semana, os resultados mostram as buscas por hora. 
Períodos entre uma semana e um ano, retornam resultados diários, entre um ano e cinco anos, resultados semanais e períodos maiores que cinco anos retornam a frequência de buscas mensal.

Figura 5: Resultados da pesquisa pelo termo "IBOV"

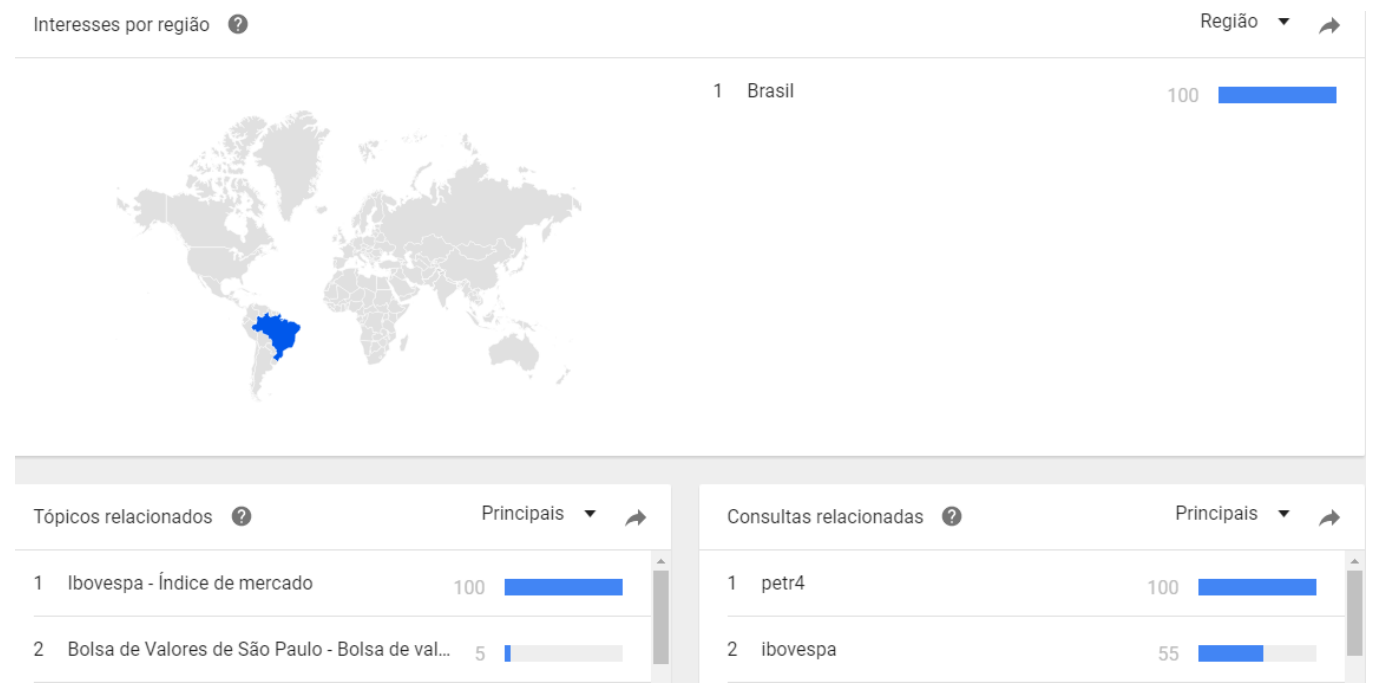

B. Google Trends - Obtenção e Tratamento dos Dados

Ao realizar uma busca no Google Trends, o site retorna uma série de dados no período selecionado onde o valor máximo é normalizado para ser igual a 100 e não no número total de buscas por data. Ou seja, a data com mais buscas no período analisado terá como retorno o valor 100 e as demais datas mostrarão o número de buscas proporcionalmente. Isso gera o problema de que seria impossível comparar os valores de buscas entre diferentes ações individualmente, pois as ordens de grandeza seriam incompatíveis. O Google Trends permite que você compare até cinco termos de busca de cada vez. Ao fazer uma busca com cinco termos, o termo mais buscado em uma data do período analisado será normalizado para o valor 100, e todos os outros pontos de dados serão proporcionais. Para possibilitar uma comparação em proporções corretas entre as 58 ações, foi necessário escolher um termo de referência, que fosse usado em todas as buscas realizadas. Ao usar o mesmo termo de referência em todas as 
buscas, garantimos que os dados retornados serão sempre proporcionais a uma mesma série de dados. O termo de referência não podia ter um volume de buscas muito acima da média, pois isso distorceria os demais dados. Por exemplo, ao usar o termo "IBOV" como referência, muitas das ações, proporcionalmente, teriam retorno zero em sua frequência de buscas, mesmo que um volume relevante de buscas por aquele termo tivesse ocorrido naquele período, já que o termo tem sempre um volume de buscas muito alto. Ao mesmo tempo, o termo de referência precisava ter um volume constante de buscas, pois ao ter muitas datas com volume de buscas zero, a comparação com as outras empresas também seria dificultada. O ticker da CSN, "CSNA3", atendia a todos os critérios acima, por isso foi escolhido como termo de referência neste trabalho.

Após realizar as buscas por grupos de ações, incluindo sempre o termo de referência, foi realizada uma busca individual do termo de referência e depois, usando as proporções de cada uma das empresas com o termo de referência, calculada a base de dados final. Os dados foram normalizados para valores com um mínimo de zero e o máximo de 1000.

\section{Resultados das Regressões com Variáveis do Google em Nível}

As Tabelas VI, VII e VIII mostram os resultados das mesmas regressões das tabelas III e IV e V, respectivamente, substituindo o logartimo da variável de buscas no Google pela variável de buscas em nível. 


\section{Tabela VI}

A coluna (1) mostra a regressão linear entre as buscas no Google em t+1 e o valor absoluto dos retornos anormais das ações em $t$, usando dados semanais que abrangem o período de janeiro de 2007 a dezembro de 2016. As estatísticas de teste são calculadas usando o método Newey-West para correção de autocorrelação serial. A coluna (2) mostra a mesma regressão adicionando dummies de ano, a (3) usando dummies de indústria, a (4) usando o volume em Reais negociado das ações no período t e a (5) mostra a regressão usando todas as variáveis das colunas (2) a (4). Os resultados abaixo apresentam o coeficiente da regressão e o erro padrão, entre parênteses. *, ** e *** representam níveis de significância de $10 \%, 5 \%$ e $1 \%$, respectivamente.

Variável Dependente: Logaritmo das Buscas no Google

\begin{tabular}{lccccc}
\hline & $(1)$ & $(2)$ & $(3)$ & $(4)$ & $(5)$ \\
\hline $\begin{array}{l}\text { Retornos } \\
\text { anormais }\end{array}$ & $0,760^{* *}$ & $\begin{array}{c}0,615^{* *} \\
(0,297)\end{array}$ & $\begin{array}{c}0,715^{* *} \\
(0,261)\end{array}$ & $\begin{array}{c}1,007^{* * *} \\
(0,272)\end{array}$ & $\begin{array}{c}0,769 * * * \\
(0,238)\end{array}$ \\
$\begin{array}{l}\text { Volume } \\
\text { Nummies de }\end{array}$ & Não & Não & Não & $\begin{array}{c}0,088^{* * *} \\
(0,023)\end{array}$ & $\begin{array}{c}0,080 * * * \\
(0,022)\end{array}$ \\
$\begin{array}{l}\text { ano } \\
\text { Indústrias }\end{array}$ & Não & Nim & Não & Não & Sim \\
$\mathrm{R}^{2}$ & 0,006 & 0,077 & 0,048 & 0,161 & Sim \\
\hline
\end{tabular}




\section{Tabela VII}

A coluna (1) mostra a regressão linear entre as buscas no Google em $t+1+j$ e o valor absoluto dos retornos anormais das ações em $\mathrm{t}$, usando dados semanais que abrangem o período de janeiro de 2007 a dezembro de 2016. As estatísticas de teste são calculadas usando o método Newey-West para correção de autocorrelação serial. A coluna (2) mostra a mesma regressão adicionando dummies de ano, a (3) usando dummies de indústria, a (4) usando o volume em Reais negociado das ações no período t e a (5) mostra a regressão usando todas as variáveis das colunas (2) a (4). Os resultados abaixo apresentam o coeficiente da regressão e o erro padrão, entre parênteses. *, ** e *** representam níveis de significância de $10 \%, 5 \%$ e $1 \%$, respectivamente.

\begin{tabular}{|c|c|c|c|c|c|}
\hline & $\begin{array}{l}\mathrm{j}= \\
\text { 1 Período a } \\
\text { frente }\end{array}$ & $\begin{array}{c}\mathrm{j}= \\
2 \text { Períodos a } \\
\text { frente }\end{array}$ & $\begin{array}{c}\mathrm{j}= \\
3 \text { Períodos a } \\
\text { frente }\end{array}$ & $\begin{array}{c}\mathrm{j}= \\
4 \text { Períodos a } \\
\text { frente }\end{array}$ & $\begin{array}{l}\quad \mathrm{j}= \\
5 \text { Períodos } \\
\text { a frente }\end{array}$ \\
\hline $\begin{array}{l}\text { Retornos } \\
\text { anormais }\end{array}$ & $\begin{array}{c}0,170 * * * \\
(0,042)\end{array}$ & $\begin{array}{c}0,138 * * * \\
(0,041)\end{array}$ & $\begin{array}{c}0,085 * * * \\
(0,041)\end{array}$ & $\begin{array}{c}0,032 \\
(0,041)\end{array}$ & $\begin{array}{c}0,133 \\
(0,041)\end{array}$ \\
\hline Volume & $\begin{array}{c}0,028 * * * \\
(0,002)\end{array}$ & $\begin{array}{c}0,028 * * * \\
(0,002)\end{array}$ & $\begin{array}{c}0,028 * * * \\
(0,002)\end{array}$ & $\begin{array}{c}0,028 * * * \\
(0,002)\end{array}$ & $\begin{array}{c}0,029 * * * \\
(0,002)\end{array}$ \\
\hline Dummies de ano & Sim & Sim & Sim & Sim & Sim \\
\hline Indústrias & Sim & Sim & Sim & Sim & Sim \\
\hline $\mathrm{R}^{2}$ & 0,068 & 0,068 & 0,068 & 0,068 & 0,067 \\
\hline
\end{tabular}




\section{Tabela VIII}

A coluna (1) mostra a regressão linear entre as buscas no Google em t+1 e o valor dos retornos anormais positivos das ações em $t$ e dos retornos anormais negativos das ações em t, usando dados semanais que abrangem o período de janeiro de 2007 a dezembro de 2016. As estatísticas de teste são calculadas usando o método Newey-West para correção de autocorrelação serial. A coluna (2) mostra a mesma regressão adicionando dummies de ano, a (3) usando dummies de indústria, a (4) usando o volume em Reais negociado das ações no período t e a (5) mostra a regressão usando todas as variáveis das colunas (2) a (4). Os resultados abaixo apresentam o coeficiente da regressão e o erro padrão, entre parênteses. *, ** e *** representam níveis de significância de 10\%, 5\% e 1\%, respectivamente.

\begin{tabular}{lccccc}
\hline \multicolumn{5}{c}{ Variável Dependente: Logaritmo das Buscas no Google } \\
\hline Retornos & $(1)$ & $(2)$ & $(3)$ & $(4)$ & $(5)$ \\
negativos & $-0,973^{* *}$ & $-0,707 * *$ & $-0,860^{* * *}$ & $-1,028^{* * *}$ & $-0,717 * * *$ \\
Retornos & $(0,301)$ & $(0,246)$ & $(0,259)$ & $(0,304)$ & $(0,242)$ \\
positivos & $0,862^{*}$ & $0,712^{*}$ & $0,787 * * *$ & $0,994 * *$ & $0,712 * * *$ \\
Volume & $(0,034)$ & $(0,281)$ & $(0,307)$ & $(0,312)$ & $(0,255)$ \\
$\begin{array}{l}\text { Dummies de } \\
\text { ano }\end{array}$ & Não & Não & Não & $0,088^{* * *}$ & $0,080^{* * *}$ \\
Indústrias & Não & Sim & Não & Não & Sim \\
$\mathrm{R}^{2}$ & Não & Não & Sim & Não & Sim \\
& 0,009 & 0,080 & 0,051 & 0,160 & 0,231 \\
\hline
\end{tabular}

